\title{
CONTABILIDADE GERENCIAL: ANÁLISE BIBLIOMÉTRICA E SISTÊMICA DA LITERATURA CIENTÍFICA INTERNACIONAL
}

\section{MANAGERIAL ACCOUNTING: BIBLIOMETRIC AND SYSTEMIC ANALYSIS OF INTERNATIONAL SCIENTIFIC LITERATURE}

Paula Renata Blonkoski

Departamento de Ciências Contábeis - Universidade Tecnológica Federal do Paraná (UTFPR)

Curitiba, PR, Brasil

E-mail: paularb_pb@hotmail.com

Ricardo Adriano Antonelli

Departamento de Ciências Contábeis - Universidade Tecnológica Federal do Paraná (UTFPR)

Curitiba, PR, Brasil

E-mail: rantonelli@utfpr.edu.br

\section{Sandro Cesar Bortoluzzi}

Departamento de Ciências Contábeis e Programa de Pós-graduação em Engenharia de Produção e

Sistemas - Universidade Tecnológica Federal do Paraná (UTFPR)

Pato Branco, PR, Brasil

E-mail: sandro@utfpr.edu.br

\section{RESUMO}

Esta pesquisa analisa a situação atual de desenvolvimento da contabilidade gerencial sob o viés da comunidade científica, por meio do instrumento de pesquisa ProKnow-C para seleção dos artigos, análise bibliométrica e sistêmica. Os principais resultados são: (i) os autores mais prolíficos foram Kari Lukka, Jonas Gerdin e Roger Burrit; (ii) Reino Unido e Austrália são as principais origens dos autores; (iii) Management Accounting Research e Accounting Organizations and Society são os periódicos de maior destaque; (iv) na maioria dos estudos não é explicitado o enquadramento metodológico; (v) planejamento estratégico, sistemas de informações gerenciais, teoria da prática e teoria institucional foram as principais teorias/conceitos utilizados nos estudos; e (vi) $41 \%$ dos estudos analisados utilizam a abordagem econômica, 39\% a abordagem social e $20 \%$ a abordagem comportamental. Conclui-se que o trabalho apresenta um panorama sobre contabilidade gerencial e contribui com futuras pesquisas sobre o tema, importante para a gestão das organizações.

Palavras-chave: Contabilidade Gerencial. Bibliometria. Análise sistêmica. Proknow-C. Revisão da literatura.

\section{ABSTRACT}

This search analyzes the current situation of management accounting development under scientific community tendency, to select articles, bibliometric and systemic analysis it was used the tool known as ProKnow-C. The main results are: (i) the most prolific authors were Kari Lukka, Jonas Gerdin and Roger Burrit; (ii) United Kingdom and Australia are the main nations where the authors come from; (iii) Accounting Research and Accounting Organizations and Society are the periodicals with greatest visibility; (iv) in most studies the methodological framework is not explained; (v) strategic planning, managed information systems, theory of practice and institutional theory were the main theories/concepts used in studies; and (vi) $41 \%$ of studies under analysis use the economic approach, 39\% social approach and $20 \%$ behavioral approach. As a conclusion, the work shows an overview about managerial accountancy and contributes with future searches related to the theme, important to business management.

Keywords: Management accounting. Bibliometry. Systemic analysis. Proknow-C. Bibliographic review.

Data de submissão: 26 de março de 2015.

Data de aprovação: 5 de setembro de 2016. 


\section{INTRODUÇÃO}

A produção científica em forma de artigos publicados em periódicos tem sua importância estabelecida no avanço das pesquisas, como fonte bibliográfica e promovendo a divulgação do conhecimento e atualização aos seus leitores (OLIVEIRA, 2002; VOLPATO, 2002; LEITE FILHO, 2008). Além disso, as publicações nacionais tendem a evidenciar as investigações científicas da realidade local, porém, almejando a inserção no cenário internacional, como forma de valorização (FREZATTI; BORBA, 2000; CALDAS, 2005; CARDOSO, PEREIRA, \& GUERREIRO, 2007).

No entanto, a publicação científica sobre a contabilidade gerencial tornou-se significativa no Brasil na primeira década do século XXI, com a inclusão de novos programas de pós-graduação e interesse dos periódicos no assunto (LEITE FILHO, 2008; NASCIMENTO, JUNQUEIRA; MARTINS 2010). Contudo, o campo de pesquisa da contabilidade gerencial no âmbito internacional, tem-se expandido desde o início de 1980, com novos tópicos de estudos e periódicos com foco exclusivo na área (HESFORD; LEE; VAN DER STEDE; YOUNG, 2007).

Com a alta propagação e a facilidade de divulgação desses artigos, emerge a necessidade de padronizar o processo de busca e organização dessas informações. Cardoso, Mendonça Neto, Riccio e Sakata (2005) ressaltam que as avaliações relativas à produção científica possibilitam a detecção de indicadores e vieses acerca do objeto pesquisado.

Com isso, a bibliometria tem sido utilizada como uma das ferramentas para atender a necessidade de padronização na análise da literatura. Segundo Café e Bräscher (2008), para que se possam recolher documentos científicos com propriedades similares, é essencial a padronização da descrição física e de conteúdo desses documentos, indicando assim itens relevantes e os conceitos de núcleo e dispersão da literatura pesquisada.

De acordo com Kobashi e Santos (2008), atualmente há um consenso entre os estudiosos que atuam na área com relação ao campo da bibliometria, que como um todo, inclui os aspectos quantitativos e os modelos da comunicação, armazenamento, disseminação e recuperação da informação científica.

$\mathrm{Na}$ atualidade, a utilização da bibliometria tem crescido na área da contabilidade, como por exemplo, a pesquisa de Oliveira (2002), Mendonça Neto (2002), Bortoluzzi, Ensslin, Ensslin e Valmorbida (2011) entre outras. No âmbito internacional esses estudos foram realizados por diversos autores, como por exemplo, Bonner, Hesford, Van Der Stede e Young (2006) no período de 1984 a 2003, Hesford et al. (2007) e Lunkes, Feliu e Rosa (2011), nos anos de 2001 a 2010.

Especificamente na literatura nacional na área de contabilidade gerencial, alguns estudos bibliométricos tem sido realizado, como por exemplo, Araújo e Silva (2010), Catapan, Loução, Carvalho e Ivasco (2010), Nascimento et al. (2010), Oliveira e Boente (2012) e Ribeiro (2013). Des te estudos, observase apenas o de Nascimento et al. (2010) com maior foco nas em características epistemológicas.

Contudo, pesquisadores denotam a importância de que além da medição das produções científicas, também sejam elaborados estudos com foco na ótica da epistemologia, pois na atualidade não existe uma literatura de análise comparativa dos padrões de pesquisa encontrados no Brasil com os adotados na academia internacional (FELIU; PALANCA, 2000; THEÓPHILO; IUDÍCIBUS, 2005; NASCIMENTO et al., 2010). A epistemologia em um sentido amplo, pode ser definida como o estudo metódico e reflexivo da ciência, 
da sua organização, de sua formação, do seu funcionamento e produtos intelectuais. Portanto, a epistemologia toma por objeto a ciência como processo, buscando conhecer e analisar suas formações e estruturas progressivas (THEÓPHILO; IUDÍCIBUS, 2005).

Cabe destacar que a pesquisa na área da contabilidade gerencial busca estabelecer essa conexão entre as produções científicas e suas aplicabilidades no ambiente das organizações, buscando servir como apoio a tomada de decisão no ambiente organizacional.

A contabilidade gerencial é capaz de fornecer ferramentas capazes de gerar informações para os usuários internos, pois ela tenta ao mesmo tempo, ser abrangente e concisa, ajustando-se constantemente para adaptar-se às mudanças tecnológicas, nas necessidades dos gestores e novas abordagens das outras áreas funcionais do negócio (LOUDERBACK et al., 2000).

Diante das mudanças organizacionais e tecnológicas das últimas décadas, o documento Management Accounting Concepts editado pelo International Federation of Accountants (IFAC) em 1998 especifica a estrutura conceitual da contabilidade gerencial, indicando as mudanças das práticas gerenciais. Em linhas gerais, o IFAC (1998, p. 94) relata que o campo da atividade organizacional envolvido como contabilidade gerencial nas organizações foi desenvolvido e reconhecido por meio de quatro estágios: (i) determinação de custos e controle financeiro (pré-1950), (ii) fornecimento de informações para gestão do planejamento em controle (até 1965); (iii) redução dos desperdícios de recursos nos processos do negócio e (iv) criação de valor por meio da efetiva utilização dos recursos.

Dentre os estágios evolutivos, a contabilidade gerencial tem se mostrado um arcabouço de ferramentas com informações à disposição dos usuários internos no processo decisório, o que tem incentivado muitas pesquisas sobre o tema. Diante da alta quantidade de publicações sobre o tema da contabilidade gerencial, surge a proposta deste estudo: qual a situação atual de desenvolvimento da pesquisa científica sobre a contabilidade gerencial a nível internacional?

O objetivo geral proposto neste trabalho é levantar a situação atual de desenvolvimento da contabilidade gerencial sob o viés da comunidade cientifica internacional. Para atender o objetivo desta pesquisa foram definidos os seguintes objetivos específicos: (i) selecionar um portfólio bibliográfico alinhado ao tema contabilidade gerencial; (ii) realizar a análise bibliométrica no portfólio bibliográfico selecionado e (iii) elaborar a análise sistêmica (análise de conteúdo), com vistas as identificar as principais tendências do tema, os principais artefatos utilizados nas pesquisas e o enquadramento metodológico dos artigos.

Considerando a necessidade de informações que suportem na tomada de decisão, a pesquisa em contabilidade gerencial, tem sido impulsionada, principalmente, pelo interesse em identificar as necessidades de informação dos gestores (AGUIAR; GUERREIRO, 2008).

Com isso, esse estudo busca identificar como a contabilidade gerencial está sendo vista no ambiente cientifico, e ainda, de que forma está sendo objeto de estudo dos pesquisadores no período entre 2007 e 2013, pois de acordo com Leite Filho (2006), a discussão sobre a produção científica na área da contabilidade é contemporânea, ou seja, seu fortalecimento ocorre nos anos 2000.

Além do exposto, esta pesquisa é justificada pela contribuição aos pesquisadores da área, que poderão ter um panorama das pesquisas em contabilidade gerencial no âmbito internacional dos últimos anos, auxiliando em suas pesquisas futuras, seja por meio da busca dos principais autores, temas, ferramentas gerenciais entre outros. Além disso, o método utilizado para o portfólio bibliográfico pode ser útil para novos 
estudos que necessitem de um maior embasamento para composição teórica, visto que uma produção científica robusta teoricamente tem papel fundamental na consolidação e evolução do conhecimento.

De um modo geral, esse estudo mostra sua importância ao contribuir com o levantamento da situação atual da contabilidade, trazendo as tendências e o que está sendo evidenciado nesses últimos seis anos de produção científica, além de observar quais as potencialidades da contabilidade gerencial. Além do exposto, os indicadores de desempenho bibliométricos analisados neste estudo podem ser úteis para avaliar a pesquisa acadêmica, bem como orientar rumos e estratégias de financiamentos de novas pesquisas.

Além da introdução, o presente estudo abordará: (i) referencial teórico; (ii) metodologia da pesquisa; (iii) resultados; (iv) considerações finais; e, (v) referências.

\section{REFERENCIAL TEÓRICO}

\section{Conceitos e objetivos da contabilidade gerencial}

A contabilidade gerencial é definida como o processo de identificação, mensuração, acumulação, análise, preparação, interpretação e comunicação de informações para a tomada de decisão do gestor (ANDERSON; NEEDLES; CADWELL, 1989; HORNGREN; SUNDEM; STRATTON, 2004; FREZATTI et al., 2007). Contudo, essas informações devem ser direcionadas a necessidade dos gestores, ou seja, no uso interno dessas informações da organização (ALMEIDA; ANTONELLI; SCHVIRCK; LONGHI, 2011).

Para Garrison, Noreen e Brewer (2007), tem sido usual a categorização da contabilidade em financeira e gerencial. Em geral, a contabilidade financeira disponibiliza relatórios para agentes externos, tais como credores e acionistas. Do outro lado, a contabilidade gerencial prepara e disponibiliza relatórios para uso interno pelos gestores.

Louderback, Holmen e Dominiak (2000) afirmam que o objetivo da contabilidade gerencial é prover informações para dar apoio às necessidades dos gestores internos da organização. Percebe-se que nos conceitos e objetivos da contabilidade gerencial, há uma conformidade entre os autores, como mostra o Quadro 1, resultante da pesquisa elaborada por Frezatti et al. (2007).

\section{Quadro 1: Conceitos e Objetivos da Contabilidade Gerencial}

\begin{tabular}{|l|l|}
\hline Fontes & Conceitos/Objetivos da contabilidade gerencial \\
\hline Anderson, Needles e Cadwell (1989). & $\begin{array}{l}\text { Processo de identificação, mensuração, acumulação, análise, preparação, } \\
\text { interpretação e comunicação da informação financeira usada pelos gestores } \\
\text { para planejamento, avaliação e controle. A informação financeira possibilita } \\
\text { aos gestores, de um lado, o uso apropriado de recursos, de outro lado, a } \\
\text { prestação de contas (accountability) decorrente desse uso. }\end{array}$ \\
\hline Louderback et al. (2000) & $\begin{array}{l}\text { Prover informações para dar apoio às necessidades dos gestores internos da } \\
\text { organização. }\end{array}$ \\
\hline Anthony e Welsch (1981) & $\begin{array}{l}\text { Fornecer informações úteis para os gestores, que são pessoas que estão } \\
\text { dentro da organização. }\end{array}$ \\
\hline Hansen e Mowen (1997) & $\begin{array}{l}\text { Identificar, coletar, mensurar, classificar, e reportar informações que são úteis } \\
\text { para os gestores no planejamento, controle e processo decisório. }\end{array}$ \\
\hline Horngren, Foster e Datar (2000). & $\begin{array}{l}\text { Medir e reportar as informações financeiras e não-financeiras que ajudam os } \\
\text { gestores a tomar decisões, para atingir os objetivos da organização. }\end{array}$ \\
\hline Horngren, Sundem e Stratton (2004) & $\begin{array}{l}\text { Processo de identificar, mensurar, acumular, analisar, preparar, interpretar e } \\
\text { comunicar informações que auxiliem os gestores a atingir objetivos } \\
\text { organizacionais. }\end{array}$ \\
\hline
\end{tabular}

Fonte: Frezatti et al., 2007. 
Na mesma linha de estudo, Souza, Lisboa e Rocha (2003) afirmam que a contabilidade gerencial tem sido reconhecida como um destacado alimentador de informações para os gestores empresariais. Corroborando tal entendimento, é determinado que por meio do uso dos instrumentos da contabilidade gerencial, é possível gerar informações contábeis para o processo de planejamento, execução e controle de suas atividades, além da avaliação de desempenho para os gestores das organizações (PADOVEZE, 2012).

$\mathrm{Na}$ atualidade é visível a transformação que vem passando o mercado, o que diretamente obriga as organizações buscar ferramentas que complementem a contabilidade financeira para a tomada de decisão. Portanto, na busca de otimizar o desempenho organizacional e acompanhar a mudança constante do mercado, as organizações se utilizam de práticas desenvolvidas pela contabilidade gerencial.

A transformação do ambiente empresarial forçou a evolução da contabilidade gerencial, de acordo com às necessidades das organizações, sendo assim, de acordo com o IFAC (1998) o campo de atividade organizacional envolvido como contabilidade gerencial foi desenvolvido e reconhecido por meio de quatro estágios: (i) determinação de custos e controle financeiro [pré-1950], (ii) fornecimento de informações para a gestão do planejamento em controle [até 1965]; (iii) redução dos desperdícios de recursos nos processos do negócio e (iv) criação de valor por meio da efetiva utilização dos recursos.

Mesmo com os estágios evolutivos da contabilidade gerencial indicados pelo IFAC (1998), a contabilidade gerencial recebeu diversas críticas de pesquisadores relacionadas à necessidade da adoção de práticas condizentes com a mudança do cenário contemporâneo, que possui alto grau de competitividade (KAPLAN, 1984; TURNEY; ANDERSON, 1989; PEAVEY, 1990).

Com isso, vários pesquisadores, buscam evoluir com estudos sobre a contabilidade gerencial, no sentido de apresentar práticas específicas consideradas adequadas e necessárias, a fim de prover um conjunto de informações de que os tomadores de decisão necessitam na condução competitiva de suas empresas (SOUZA et al., 2003).

\section{BIBLIOMETRIA}

O termo bibliometria surgiu pela primeira vez no Traité de Documentatión, em 1934, indicado por Paul Otlet, onde afirmava que a bibliometria era parte definida da bibliologia, que se ocupa da medida ou quantidade aplicada aos livros. No entanto, a difusão deste termo ocorreu por meio de Alan Pritchard em 1969, que descrevia a bibliometria como os estudos que buscavam quantificar os processos de comunicação escrita. Ele foi o responsável pela popularização da bibliometria em substituição ao termo 'bibliografia estatística', que era utilizado desde 1922, quando mencionado por Edward Wyndhan Hulme (VANTI, 2002).

A bibliometria é definida como o conjunto de técnicas e procedimentos matemáticos e estatísticos utilizados para medir a difusão da produção do conhecimento científico, em livros, artigos, documentos, revistas, autores e usuários (ARAÚJO, 2006; TAGUE-SUTCKIFFE, 1992; MACIAS-CHAPULA, 1998; SENGUPTA, 1992). Na mesma linha, Macias-Chapula (1998) cita que a bibliometria estuda os aspectos quantitativos da produção, da disseminação e do uso da informação registrada.

Segundo Vanti (2002) a bibliometria é fundamentada sobre três leis clássicas, a Lei de Lotka, Lei de Zipf e Lei de Bradford, estas apresentam duas variáveis, uma quanto ao conjunto de produtores formado por periódicos e autores e outra quanto ao conjunto de produtos, formado por documentos e citações. 
Lei de Lotka: também denominada como Lei do Quadrado Inverso, buscar descrever a produtividade dos autores mediante um modelo de distribuição de tamanho e frequência para um determinado número de publicações (ALVARADO, 2002).

O mesmo autor ainda indica, que desde 1926 diversos estudos têm sido conduzidos na investigação da produtividade dos autores em distintas disciplinas. No entanto, autores têm criticado e levantado algumas falhas na lei, como exemplo, Rao (1986, p.182) acredita que essa lei "[...] é baseada em um conjunto pouco potente de dados e não foi testado estatisticamente". Price, a partir de estudos realizados entre 1965 e 1971 procurou aperfeiçoar a Lei de Lotka, formulando a Lei do Elitismo de Price.

Lei de Zipf (ou Lei de Mínimo Esforço): consiste em medir a frequência do aparecimento das palavras em vários textos, gerando uma lista ordenada de termos em uma determinada disciplina ou assunto.

Lei de Bradford (ou Lei de Dispersão): permite que, diante a medição da produtividade das revistas, estabelecer o núcleo e às áreas de dispersão sobre um determinado assunto em um mesmo conjunto de revistas. No entanto, alguns autores, como exemplo Pinheiro (1983), trazem críticas quanto à eficiência da Lei de Bradford, alegando que ela não mostra a realidade do comportamento da literatura científica.

Com tudo, a bibliometria permite analisar quais autores publicaram sobre determinado tema, quais se destacaram, quais mais publicaram, tendências de temas entre outros. Cabe destacar, que em estudos bibliométricos é necessário, primeiramente, descrever os elementos constitutivos das bases de dados (os dados de input), de modo a estabelecer conjuntos, os quais se aproximam por "semelhanças de família", no sentido proposto por Wittgenstein (1996).

\section{ANÁLISE SISTÊMICA}

A análise sistêmica constitui uma metodologia de pesquisa usada para descrever e interpretar o conteúdo de toda classe de documentos e textos, que por meio de tal análise, é possível conduzir as descrições sistemáticas, qualitativas ou quantitativas (MORAES, 1999).

Neste contexto, Bardin (2009) cita que descrever a história da análise de conteúdo é essencialmente seguir passo a passo o crescimento quantitativo e a diversificação qualitativa dos estudos empíricos, de modo a posteriormente observar como os materiais foram aperfeiçoados.

A análise sistêmica (de conteúdo) é um instrumento de construção de conhecimento, pois evidência o resultado objetivado na pesquisa permitindo ao pesquisador conhecer o estado da arte do tema desejado, que neste artigo tem como foco a contabilidade gerencial. 


\section{ENQUADRAMENTO METODOLÓGICO}

Quanto à natureza do objetivo a pesquisa tem caráter exploratório, pois busca levantar informações sobre um determinado objeto (SEVERINO, 2007), e, descritivo que de acordo com Gil (1999) tem como objetivo primordial a descrição das características de determinada população ou fenômeno.

A coleta de dados é secundária por meio da análise dos artigos publicados nos periódicos internacionais sobre o tema contabilidade gerencial. A pesquisa bibliográfica é aquela que se realiza a partir do registro disponível decorrente das pesquisas anteriores (SEVERINO, 2007).

A abordagem do problema é quantitativa e qualitativa. A fase quantitativa é caracterizada por empregar instrumentos estatísticos (RICHARDSON, 1999). No presente estudo, a fase quantitativa é realizada por meio da análise bibliométrica, com o objetivo de quantificar a produção científica dos artigos selecionados (MARTINS; SILVA, 2005, VANTI, 2002). No estudo em questão, foram tabulados os seguintes dados do portfólio bibliográfico: autores mais prolíficos, análise temporal, palavras-chave mais utilizadas, países de origem dos autores, periódicos com maior número de artigos no portfólio bibliográfico e grau de relevância dos artigos.

A fase qualitativa é caracterizada pela análise de conteúdo dos artigos do portfólio bibliográfico, conforme estabelece Bardin (2009). Nesta etapa realizou-se o mapeamento dos artigos com o propósito de identificar as teorias/conceitos base e a abordagem utilizada nos estudos.

\section{PROCEDIMENTOS PARA COLETA E ANÁLISE DOS DADOS}

Este estudo utiliza como instrumento de pesquisa o ProKnow-C (Knowledge Developmend ProcessConstructivist) proposto por Ensslin et al. (2010), o qual foi adaptado para a realização da presente pesquisa. As adaptações realizadas foram: (i) no processo de busca algumas etapas foram suprimidas e outras acrescentadas para atender as finalidades da pesquisa; (ii) na análise bibliométrica deixou-se de realizar a análise das referências do portfólio bibliográfico; e, (iii) na análise sistêmica o processo utilizado pelos autores da ferramenta concentra-se em uma temática diferente do presente estudo.

Esse instrumento foi utilizado em estudos precedentes por vários autores (AFONSO; SOUZA; ENSSLIN; ENSSLIN, 2011; BORTOLUZZI et al., 2011; VILELA, 2012; VALMORBIDA, ENSSLIN; ENSSLIN, 2013). Esse processo constitui uma metodologia de construção de conhecimento, conforme Figura 1 , estruturado em três etapas: (i) seleção do portfólio bibliográfico por meio de um processo estruturado; (ii) análise bibliométrica do portfólio bibliográfico; e, (iii) análise sistêmica (de conteúdo) do portfólio bibliográfico. 
Figura 1: Instrumentos de pesquisa utilizados neste estudo.

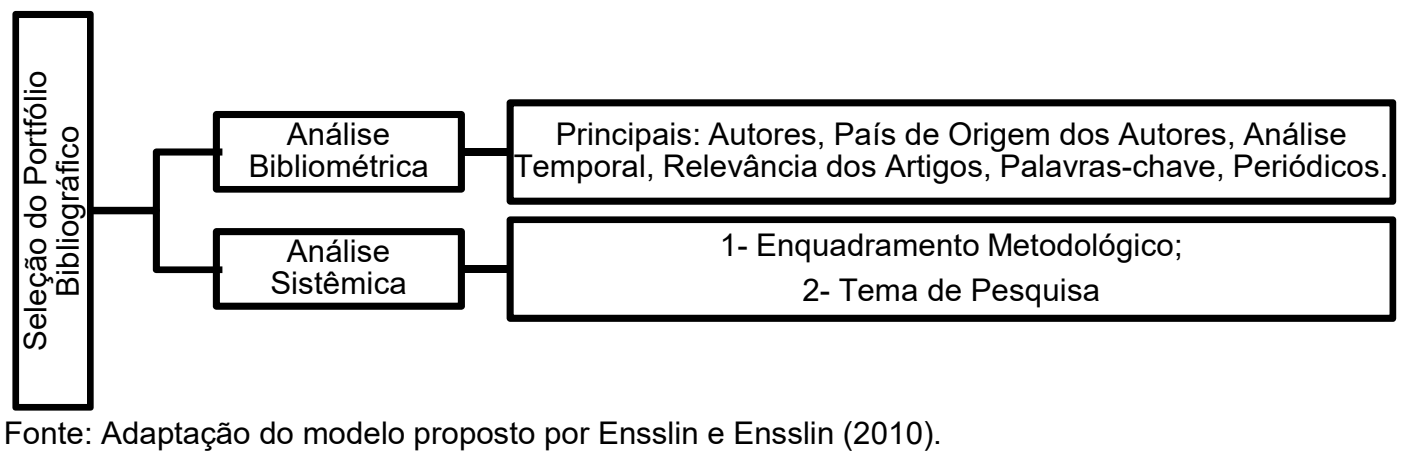

Como mostra a 
Figura 1, primeiramente faz-se a seleção do portfólio bibliográfico e na sequência elabora-se a análise bibliométrica e a análise sistêmica (de conteúdo).

\section{Seleção dos artigos para compor o portfólio bibliográfico}

Para iniciar a etapa de seleção do Portfólio Bibliográfico foi necessário definir a palavra-chave. Neste estudo, a palavra-chave determinada foi "management accounting". Após a definição da palavra-chave a ser empregada, foi necessário definir as bases de dados para realizar a busca de artigos. Foram selecionadas a base Scopus (Scopus Database) e Web of Science- ISI (International Scientific Information). Ambas, bases de busca eletrônica de publicações científicas, consideradas as mais relevantes no contexto internacional. O processo de seleção do portfólio bibliográfico seguiu de acordo com os passos definidos na Figura 2.

\section{Figura 2: Definição do processo de busca dos artigos para seleção do portfólio bibliográfico}

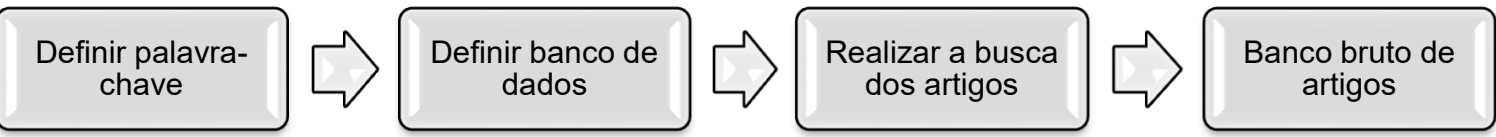

Fonte: Adaptação do modelo proposto por Ensslin e Ensslin (2010).

A busca para selecionar os artigos nas bases citadas, foi realizada pelos seguintes critérios: (i) emprego do termo "management accounting" apenas no título do artigo; (ii) somente artigos relacionados com a área Social Sciences; (iii) período entre 2007 e 2013. O processo de busca retornou um total de 341 artigos, sendo $56 \%$ na Base Scopus e $44 \%$ na Base ISI, o que constituiu o banco de artigos bruto.

O banco de artigos bruto (341 artigos) foi exportado para um software de gerenciamento bibliográfico. Após a exportação do banco de artigos bruto (341 artigos), realizou-se um processo de filtragem, utilizandose dos seguintes critérios, conforme evidenciado na Figura 3 (i) exclusão dos artigos duplicados. Essa etapa foi necessária, pois a busca foi realizada em duas bases de dados e o artigo poderia retornar em duplicidade. Nesta etapa foram excluídos 73 artigos; (ii) exclusão pelo tipo de publicação. Essa etapa foi necessária para manter apenas os artigos científicos, pois não interessava para a presente pesquisa livros ou capítulos de livros. Nesta etapa foram excluídos 73 artigos. Após esse processo de filtragem restaram 195 artigos dos 341 artigos do banco de artigos bruto.

Figura 3: Processo de Filtragem dos Artigos do Banco Bruto de Artigos

\begin{tabular}{|c|}
\hline 341 Artigos exportados para o Software de Gerenciamento Bibliográfico \\
Análise de Duplicidade \\
73 artigos excluídos por duplicidade \\
Análise Tipo da Publicacãa \\
73 artigos excluídos por estarem publicados em forma de seção de livro e/ou livro \\
Banco Bruto de Artiaos \\
195 artigos mantidos no banco bruto de artigos.
\end{tabular}

Fonte: Dados da Pesquisa. 
Na sequência fez-se necessário utilizar outros critérios para filtragem dos artigos. Esses critérios foram escolhidos para garantir um portfólio bibliográfico relevante sobre o tema contabilidade gerencial no contexto internacional. Sendo assim, buscou-se estabelecer critérios para garantir artigos de qualidade e que tivessem disponibilidade do texto completo, publicados em periódicos relevantes e de autores prolíficos sobre o tema contabilidade gerencial.

Neste sentido, estabeleceu-se os seguintes critérios para filtragem dos 195 artigos remanescentes: (i) reconhecimento científico dos artigos; (ii) disponibilidade do conteúdo integral; r, (iii) elaboração do banco de autores com reconhecimento confirmado.

Em relação ao primeiro critério, reconhecimento científico dos artigos, buscou-se o número de citações de cada artigo no Google Acadêmico. A escolha do Google acadêmico foi a alternativa encontrada para padronizar o número de citações, já que a busca foi realizada em duas bases de dados diferentes. Após buscar o número de citações de cada artigo no Google acadêmico, que para esse artigo, foi considerado como critério para determinar o reconhecimento científico dos artigos, fez-se necessário um corte para estabelecer um conjunto de artigos com reconhecimento científico e um conjunto de artigos com reconhecimento científico não confirmado. Para realizar essa atividade utilizou-se como critério o princípio de Pareto (1897). Sendo assim, foi selecionado um conjunto de 45 artigos (dos 195 remanescentes) que representa $80 \%$ do total das citações e restaram 150 artigos (dos 195 remanescentes) que representam $20 \%$ do total das citações. Por fim, pelo critério utilizado para determinar o reconhecimento científico, restaram 45 artigos com reconhecimento científico confirmado e 150 artigos com reconhecimento científico não confirmado.

O segundo critério consistiu na verificação da disponibilidade integral dos artigos, sendo que dos 45 artigos com reconhecimento científico restaram 39, ou seja, 6 artigos não foi possível encontrar o texto completo, pois as bases de dados utilizadas para a busca inicial são bases de resumos.

O terceiro critério foi constituir o banco de autores que publicaram os 39 artigos com reconhecimento científico e texto completo. $O$ banco de autores foi desenvolvido para participar de uma etapa posterior do processo de seleção do portfólio bibliográfico. O uso das informações geradas nessa etapa do processo será explicitado na sequência.

Neste momento do processo, 39 artigos foram selecionados. Esses 39 artigos apresentam reconhecimento científico pelos critérios utilizados nesta pesquisa e existe a disponibilização dos textos completos para análise.

Apesar do processo ter filtrado 39 artigos com texto completo e com reconhecimento científico, ficaram 150 artigos que se denominou como sendo artigos com reconhecimento científico não confirmado. Estes artigos foram direcionados para uma reanálise utilizando-se os seguintes critérios: (i) inclusão de artigos em que os autores estão no banco de autores (esse banco de autores refere-se aos autores dos 39 artigos com reconhecimento científico confirmado e com texto completo disponível); (ii) inclusão de artigos em que o tempo de publicação é menor que 2 anos; e, (iii) inclusão de artigos que foram publicados em periódicos com JCR (Journal Citation Reports) maior que 1.

No primeiro critério da reanálise dos artigos buscou-se incorporar as pesquisas de autores que já tinham trabalhos no portfólio bibliográfico com reconhecimento científico. Considerou-se neste critério que os autores que tinham trabalhos no portfólio de 39 artigos com reconhecimento científico, deveriam ser 
considerados em função de sua relevância como autor para o tema contabilidade gerencial, mesmo que esses outros trabalhos não tivessem reconhecimento científico. Nesta etapa de reanálise foram incorporados 14 artigos científicos publicados por autores relevantes para o tema contabilidade gerencial.

No segundo critério foram incorporados artigos recentes (menos de 2 anos de publicação). Essa escolha é justificada, pois artigos recentes ainda não tiveram o tempo necessário para serem citados por outros trabalhos científicos. Nesta etapa foram incorporados 2 artigos recentes que não tiveram tempo para serem citados.

No terceiro critério foram incorporados artigos de periódicos relevantes para a área de contabilidade gerencial. Sendo assim, mesmo sem reconhecimento científico, foram incorporados os artigos publicados em periódicos com JCR maior que 1. Nesta etapa foram incorporados 4 artigos publicados em periódicos relevantes para a área.

Sendo assim, somando-se 39 artigos selecionados pelo reconhecimento científico e com a disponibilização dos textos completos, mais 20 artigos selecionados pela reanálise, o portfólio bibliográfico selecionado ficou em 59 artigos sobre o tema contabilidade gerencial, que atendeu os critérios utilizados nesta pesquisa.

\section{Procedimento para a análise bibliométrica}

Com a seleção do portfólio bibliográfico realizou-se a análise bibliométrica dos artigos para evidenciar os seguintes aspectos: (i) principais autores, (ii) país de origem dos autores, (iii) análise temporal, (iv) reconhecimento científico dos artigos, (v) palavras-chave mais recorrentes, e, (vi) principais periódicos. Para realizar a análise bibliométrica utilizou-se o software de gerenciamento bibliográfico citado nos procedimentos para seleção do portfólio bibliográfico. Esse software apoiou na tabulação e análise dos principais autores, análise temporal, palavras-chave mais recorrentes e principais periódicos do portfólio. Adicionalmente, utilizou-se o Microsoft excel para as demais tabulações e análises, tais como: país de origem dos autores e reconhecimento científico dos artigos. 


\section{Procedimentos para análise sistêmica}

A análise sistêmica foi realizada por meio de duas etapas: (i) análise do enquadramento metodológico dos artigos; e, (ii) análise das teorias/conceitos base para realização dos estudos.

$\mathrm{Na}$ primeira etapa, a fim de identificar o enquadramento metodológico dos artigos do portfólio bibliográfico este estudo adaptou o modelo proposto por Ensslin e Ensslin (2010) e contemplou os seguintes tópicos: (i) natureza do objetivo; (ii) natureza do trabalho teórico; (iii) natureza do trabalho prático; (iv) coleta de dados; (v) abordagem do problema; e, (vi) instrumentos de pesquisa.

$\mathrm{Na}$ segunda etapa, identificou-se as principais tendências da contabilidade gerencial sob o viés da comunidade científica. Para isso, realizou-se a leitura dos artigos, evidenciando a teoria/conceito base de estudo. Adicionalmente, buscou-se classificar os artigos no uso da abordagem econômica, social ou comportamental, conforme conceituação apresentada no trabalho de Frezatti et al. (2009).

\section{RESULTADOS}

\section{Resultado da análise bibliométrica}

Principais autores

A primeira análise bibliométrica realizada foi em relação aos autores mais prolíficos do portfólio bibliográfico (59 artigos). $\mathrm{Na}$

Tabela 11 apresenta-se o autor, a quantidade de artigos publicados, o percentual de representatividade do autor e o percentual de representatividade acumulado.

Tabela 1: Número de artigos publicados por Autor

\begin{tabular}{lccc}
\hline \multicolumn{1}{c}{ Autor } & $\begin{array}{c}\text { Quantidade de artigos } \\
\text { publicados }\end{array}$ & \% do total de autores & $\begin{array}{c}\text { \% representado } \\
\text { na amostra }\end{array}$ \\
\hline Burrit, R.L. & 04 & 3,77 & 3,77 \\
Gerdin, J. & 04 & 3,77 & 7,55 \\
Lukka, K. & 04 & 3,77 & 11,32 \\
Englund, H. & 03 & 2,83 & 14,15 \\
Modell, S. & 03 & 2,83 & 16,98 \\
Tsamenyi, M. & 03 & 2,83 & 19,81 \\
Autores com 02 Publicações & 10 & 1,88 & 29,25 \\
Autores com 01 Publicação & 90 & 0,94 & $100 \%$ \\
Total & 106 & - & - \\
\hline
\end{tabular}

Fonte: Dados da pesquisa.

Foram identificados 106 autores no portfólio bibliográfico selecionado (59 artigos). No entanto, optouse em mostrar na Tabela 1, os autores com maior número de publicações, os quais corresponderam à aproximadamente $20 \%$ da amostra. 
País de origem dos autores

Nesta seção, a análise bibliométrica identificou a quantidade de autores por país de origem. A quantidade de autores por país é: Reino Unido (26 autores), Austrália (14 autores), Suécia, Finlândia e Alemanha (08 autores), Dinamarca (07 autores), Itália e Holanda (05 autores), França e Brasil (04 autores), e, outros Países (42 autores).

Foi possível perceber que 26 autores são do Reino Unido, totalizando $24,52 \%$ da amostra total de autores. Em segundo lugar vem à Austrália com 14 autores, correspondendo a 13,21\%, da amostra. Somando-se os autores do Reino Unido com os da Austrália, tem-se praticamente $38 \%$ dos autores oriundos desses dois locais.

\section{Análise temporal dos artigos}

A análise temporal buscou evidenciar os períodos mais prolíficos de publicações sobre o tema contabilidade gerencial, conforme apresentado na Tabela 2.

Tabela 2: Quantidade de Artigos do Portfólio Bibliográfico publicados por ano

\begin{tabular}{lcccccccc}
\hline Ano & $\mathbf{2 0 0 7}$ & $\mathbf{2 0 0 8}$ & $\mathbf{2 0 0 9}$ & $\mathbf{2 0 1 0}$ & $\mathbf{2 0 1 1}$ & $\mathbf{2 0 1 2}$ & $\mathbf{2 0 1 3}$ & Total \\
\hline Quantidade de Artigos & 11 & 09 & 11 & 06 & 11 & 07 & 04 & 59 \\
\hline
\end{tabular}

Fonte: Dados da pesquisa.

Os anos de 2007, 2009 e 2011 foram os com maior produtividade, com 11 publicações cada. Cotejando com os 15 artigos de maior reconhecimento científico, 8 deles foram publicados em 2007, 5 em 2008 e 2 em 2009.

Artigos de maior relevância no portfólio bibliográfico

Os artigos mais relevantes do portfólio bibliográfico são: (i) "Management accounting as Practice" de Ahrens \& Tomas, publicado em 2007 com 240 citações; (ii) "Defining management accounting constructs: A methodological note on the risks of conceptual misspecification" de Bisbe, Batista-Foguet \& Chenhall, publicado em 2007 com 125 citações; e, (iii) "Management accounting change and stability: Loosely coupled rules and routines in action" de Lukka, publicado em 2007 com 121 citações.

Cabe salientar que o autor Kari Lukka é um dos autores de maior destaque no portfólio bibliográfico selecionado, e ainda, destaca-se que o mesmo escreveu o terceiro artigo de maior relevância do portfólio.

Palavras-chave mais utilizadas

O próximo passo consistiu em analisar as palavras-chave presentes no portfólio bibliográfico. Constatou-se que dos 59 artigos, 14 deles não utilizaram palavras-chave no texto. No entanto, os 45 artigos restantes foram analisados por se tratarem de uma amostra relativamente grande, ou seja, $76,27 \%$ dentro do portfólio bibliográfico. No total foram encontradas 217 palavras-chave, o que perfaz uma média de 4,76 por 
artigo publicado. As palavras-chave tem o objetivo de apontar resumidamente o conteúdo, métodos de pesquisa e/ou ferramentas utilizadas nos estudos.

As palavras-chave mais utilizadas no portfólio foram "management accounting" e "strategic management accounting", o que fortalece a seleção do Portfólio Bibliográfico, pois está condizente com o foco da pesquisa.

\section{Periódicos relevantes do Portfólio Bibliográfico}

A Tabela 3 evidencia os 17 periódicos do portfólio bibliográfico. O periódico de maior destaque no portfólio bibliográfico selecionado (59 artigos) foi o "Management Accounting Research" com 19 artigos publicados. No estudo realizado por Frezatti e Borba (2000), este periódico tem a área de atuação resumida e compreende publicação de "artigos sobre a contabilidade gerencial incluindo estudos de caso, estudo de campo, estudos empíricos, comentários e notas", e seu enfoque principal é contabilidade gerencial e de custos.

O segundo periódico "Accounting Organizations and Society" com 9 publicações, publica "artigos relacionados com o papel social da contabilidade, comportamento humano, os processos e estruturas organizacionais e as mudanças no processo político social das empresas", e tem o enfoque principal em contabilidade geral.

Tabela 3: Periódicos de destaque no Portfólio Bibliográfico

\begin{tabular}{lr}
\hline Periódicos & Artigos \\
\hline Management Accounting Research & 19 \\
Accounting Organizations and Society & 09 \\
Critical Perspectives on Accounting & 06 \\
Accounting Auditing \& Accountability Journal & 05 \\
Qualitative Research in Accounting and Management & 03 \\
British Accounting Revie, European Accounting Review, Industrial Management and Data Systems, & 02 \\
International Journal of Accounting Information Systems, Journal of Cleaner Production. & 01 \\
Inzinerine Ekonomika-Engineering Economics, Australian Accounting Review, Contemporary Accounting \\
Research, International Business Review, Journal of Accounting, Auditing and Finance, Journal of Business
\end{tabular}

Fonte: Dados da pesquisa.

$\mathrm{Na}$ comparação com os autores do portfólio bibliográfico, constatou-se que Kari Lukka, um dos autores em destaque com quatro publicações, publicou o artigo "Management accounting change and stability: Loosely coupled rules and routines in action", terceiro artigo mais citado, no periódico de maior destaque "Management Accounting Research". Além disso, o artigo com mais citações dentro do portfólio "Management Accounting as Practice" é de autoria de Ahrens \& Champman, que foi publicado no segundo periódico de maior destaque. 


\section{Resultados da análise sistêmica}

A análise sistêmica ocorreu em duas etapas: (i) enquadramento metodológico dos artigos do portfólio bibliográfico, (ii) análise sistêmica do tema de pesquisa da contabilidade gerencial.

\section{Enquadramento Metodológico dos artigos do Portfólio Bibliográfico}

Nesta seção será apresentada a análise sistêmica dos artigos do portfólio bibliográfico, a partir do modelo adaptado proposto por Ensslin e Ensslin (2010). A identificação da classificação, quanto ao enquadramento metodológico, ocorreu na explicitação do autor quanto ao enquadramento metodológico utilizado, ou seja, não foi realizada a classificação quando os autores não explicitaram no artigo o enquadramento metodológico da pesquisa. Nestes casos, deixou-se a expressão "não explicitado". No Quadro 2 apresenta-se a análise quanto o enquadramento metodológico dos estudos.

\section{Quadro 2: Enquadramento Metodológico dos Artigos do Portfólio Bibliográfico}

\begin{tabular}{|c|c|c|c|c|}
\hline \multicolumn{5}{|c|}{ NATUREZA DO OBJETIVO } \\
\hline Exploratória & Descritiva & Exploratória/Descritiva & Não Explicitado & Total \\
\hline 14 & 01 & 10 & 34 & 59 \\
\hline \multicolumn{5}{|c|}{ NATUREZA DO TRABALHO - TEÓRICO } \\
\hline Conceitual & Ilustrativo & Conceitual Aplicado & Não Explicitado & Total \\
\hline 12 & 01 & 01 & 45 & 59 \\
\hline \multicolumn{5}{|c|}{ NATUREZA DO TRABALHO - PRÁTICO } \\
\hline Estudo de Caso & Survey & Experimental & Não Explicitado & Total \\
\hline 30 & 05 & - & 24 & 59 \\
\hline \multicolumn{5}{|c|}{ COLETA DE DADOS } \\
\hline Primários & Secundários & Ambos & Não Explicitado & Total \\
\hline 20 & 05 & 13 & 21 & 59 \\
\hline \multicolumn{5}{|c|}{ ABORDAGEM DA PESQUISA } \\
\hline Qualitativa & Quantitativa & Qualitativa/ Quantitativa & Não Explicitado & Total \\
\hline 10 & 09 & 05 & 35 & 59 \\
\hline \multicolumn{5}{|c|}{ INSTRUMENTO DE PESQUISA } \\
\hline Questionário & Entrevista & Análise Documental & Quest./Entr. & Total \\
\hline 04 & 09 & 07 & 04 & \multirow{3}{*}{59} \\
\hline Quest./ Análise & \multicolumn{2}{|c|}{ Quest./ Entrevista/ Análise Documental } & Não Explicitado & \\
\hline 06 & & 03 & 24 & \\
\hline
\end{tabular}

Fonte: Dados da pesquisa, 2013.

Cabe salientar que na análise de enquadramento metodológico foram levadas em consideração somente as identificações explícitas nos artigos do portfólio bibliográfico, ou seja, como o próprio autor da pesquisa descreveu a metodologia de seu trabalho. 
Destaca-se que quando considerado somente as pesquisas que explicitam o enquadramento metodológico, tem-se os seguintes resultados: (i) $56 \%$ dos estudos são exploratórios; (ii) $85 \%$ são conceituais; (iii) $85 \%$ são estudos de caso; (iv) $53 \%$ das pesquisas são realizadas utilizando-se de dados primários; (v) $42 \%$ dos estudos utilizam uma abordagem qualitativa; e, (vi) 15\% das técnicas de pesquisa utilizadas são entrevistas.

Essa análise faz refletir sobre as possibilidades de pesquisa em contabilidade gerencial, pois lida com problemas internos das organizações, sendo que essas informações muitas vezes só podem ser analisadas por instrumentos qualitativos e por meio de estudos de caso, conforme evidencia a presente pesquisa.

Análise sistêmica do tema de pesquisa da contabilidade gerencial.

Nesta segunda etapa foram realizadas duas análises. A primeira em relação à teoria/conceito base utilizada nas pesquisas do portfólio bibliográfico. A segunda sobre as abordagens utilizadas na pesquisa econômica, social ou comportamental (FREZATTI; et al., 2009).

Em relação à primeira análise, apresenta-se na Tabela 4 a teoria ou o conceito base utilizados nas pesquisas selecionadas.

Tabela 4: Teoria ou Conceito base do Estudo

\begin{tabular}{lc|lc}
\hline Teoria ou Conceito base do Estudo & Quant. & Teoria ou Conceito base do Estudo & Quant. \\
\hline Planejamento Estratégico & 09 & Teoria Estrutura - Agência & 03 \\
Sistemas de Informações Gerenciais & 06 & Perspectiva Social & 02 \\
Teoria da Prática & 06 & Validade Preditiva & 02 \\
Teoria Institucional & 05 & Pesquisa de Métodos Mistos - Triangulação & 02 \\
Ferramentas da Contabilidade Gerencial & 05 & Teoria da Estruturação & 02 \\
Contabilidade de Gestão Ambiental - EMA & 04 & Pesquisas Qualitativas & 02 \\
Teoria Ator-Rede & 03 & Teoria Intervencionista & 01 \\
Teoria da Contingência & 03 & Frugalidade Corporativa & 01 \\
Pesquisa Interpretativa & 03 & & \\
\hline TOTAL GERAL $\rightarrow$ & &
\end{tabular}

Fonte: Dados da Pesquisa.

Por meio desta pesquisa foi possível evidenciar que o Planejamento Estratégico corresponde a $15,25 \%$ da amostra e que a literatura sobre a contabilidade gerencial estratégica vem "ganhando espaço" entre os pesquisadores. O planejamento estratégico foi o de maior destaque dentro do portfólio, afirmando assim a argumentação de Frezatti et al. (2009) quanto a importância do planejamento dentro das organizações.

Destacam-se também os estudos que tiveram como base os Sistemas de Informações Gerenciais (SIG) e a Teoria da Prática, que juntos corresponderam a 10,17\% da amostra cada um. A teoria da prática constitui, de fato, uma ampla família de abordagens teóricas ligadas por uma rede de semelhanças históricas e conceituais. A contribuição de uma abordagem prática é descobrir que por trás de todos os recursos, há sempre o trabalho e esforço de alguém. Estudos como de Malmi \& Granlund (2009) abordam a necessidade de uma teoria para a utilização da prática mais detalhada, orientando qual prática utilizar e em que 
circunstância, o que poderia ser útil na determinação de qual prática ser utilizada nas entidades. Ahrens \& Chapman (2007) afirmam que a teoria da prática, através das práticas do controle gerencial, é essencial para a organização, pois ajudam a trazer a conexão entre as diversas atividades dos membros organizacionais. Abrahamsson, Englund, Gerdin (2011) afirmam que as práticas contábeis são um importante meio de legitimação ou deslegitimação, e auto percepção de uma organização.

Um dos desafios atuais da contabilidade gerencial é encontrar uma teoria e prática que considerem o ambiente de competição em que é utilizada, de modo que, as mudanças organizacionais exigem uma amplitude adequada para o tratamento eficaz dos problemas gerenciais contemporâneos (FREZATTI; et al., 2009).

Em relação aos sistemas de informações gerenciais, o mais utilizado nas pesquisas foi o Enterprise Resource Planning (ERP), estes são eficientes no que diz respeito às transações e gerar informações aos gestores, pois compreende as organizações em todos os processos. Portanto, pode-se afirmar que os SIG's tem papel importante nas entidades, pois, são responsáveis pelas informações para tomada de decisão dos gestores. No entanto, é necessário ter uma atenção quanto à escolha do SIG utilizado, este deve atender aos gestores, fornecendo informações adequadas e condizentes com a estrutura da entidade.

Em relação à segunda análise evidenciam-se na Tabela 5 as abordagens utilizadas nos estudos selecionados.

Tabela 5: Abordagens utilizadas nos estudos

\begin{tabular}{|c|c|c|}
\hline Abordagem & Quantidade & $\%$ \\
\hline Econômica & 24 & $41 \%$ \\
\hline Social & 23 & $39 \%$ \\
\hline Comportamental & 12 & $20 \%$ \\
\hline Total & 59 & $100 \%$ \\
\hline
\end{tabular}

Fonte: Dados da pesquisa.

Conforme evidenciado no capítulo de metodologia da pesquisa, buscou-se realizar a classificação das pesquisas selecionadas em função da abordagem econômica, social ou comportamental, conforme conceituação apresentada no trabalho de Frezatti et al., (2009). A abordagem mais utilizada nos estudos é a abordagem econômica, seguida da abordagem social e comportamental.

A abordagem comportamental, segundo Frezatti (2009) está relacionada com o comportamento do indivíduo, ou seja, como as características cognitivas dos gestores influenciam na utilização da contabilidade gerencial, tal qual como os entendimentos dos vieses morais afetam a utilização dos relatórios contábeis na tomada de decisão. Corroborando, Kahneman e Tversky $(1979 ; 1981)$ indicam que existem outros elementos subjetivos incorporados pelos tomadores de decisão que afetam a sua racionalidade. Outras questões dessa abordagem podem compreender a relação entre a percepção de justiça do indivíduo, bem como suas questões éticas e morais e questões relacionadas com o poder e obediência e sua relação nos sistemas de contabilidade gerencial. Yazdifar et al. (2008) argumenta a importância dos valores culturais nas instituições 
para a mudança das práticas contábeis, porém as regras e normas estabelecidas por um poder maior prevalece

Por segundo, a abordagem econômica revela como as organizações utilizam as ferramentas e sistemas na busca de otimização no desempenho econômico, utilizando eficientemente os recursos econômicos da entidade (FREZATTI, 2009).

A terceira e última refere-se à abordagem social, que evidencia, no contexto organizacional das empresas, a relação de força entre os grupos de pessoas influenciam direta ou indiretamente na definição do método de apoio utilizado na tomada de decisão (FREZATTI, 2009). Para Stergiou et al. (2013) existe a afirmação de que mesmo que as estruturas empurrem os agentes em determinadas direções é necessário que os agentes interajam. E, mudanças nas práticas não dependem das organizações, mas sim das medidas dos agentes. Assim como os movimentos sociais em geral designam um tipo de ação coletiva voltada para as mudanças dirigidas por um ator social (MARTELETO, 2001).

\section{CONSIDERAÇÕES FINAIS}

A presente pesquisa selecionou 59 artigos científicos por meio de um processo estruturado denominado Proknow-C (Knowledge Developmend Process-Constructivist) proposto por Ensslin e Ensslin (2010). A partir do portfólio selecionado foi realizado a análise bibliométrica e sistêmica.

A análise bibliométrica permitiu identificar as principais características das produções científicas relevantes sobre contabilidade gerencial no contexto internacional, com destaque para os seguintes resultados: (i) os autores mais prolíficos foram Kari Lukka, Jonas Gerdin e Roger L. Burrit, que juntos produziram $27 \%$ do total da amostra; (ii) Reino Unido e Austrália são as principais origens dos autores, com 38\% da amostra; (iii) Management Accounting Research e Accounting Organizations and Society são os periódicos de maior destaque; e (iv) os autores brasileiros tiveram apenas um artigo publicado no período de 2007 a 2013, que discute a importância do planejamento estratégico e orçamentário nas organizações.

$\mathrm{Na}$ análise sistêmica buscou identificar o enquadramento metodológico utilizado pelos pesquisadores, no entanto, grande parte dos artigos do portfólio bibliográfico não explicitou seu enquadramento metodológico conforme o modelo proposto por Ensslin e Ensslin (2010). Utilizando somente as terminologias pesquisa empírica, e/ou revisão de literatura, e/ou estudo de caso e/ou outras definições isoladas. Contudo, foi possível perceber que o estudo de caso foi à natureza do trabalho prático mais utilizado e explicitado nas pesquisas.

A análise do enquadramento metodológico das pesquisas anteriores sobre contabilidade gerencial, permitiu concluir que no contexto internacional os autores não utilizam a prática de explicitar o a abordagem do problema, a natureza do objetivo e os instrumentos para coleta e análise dos dados.

Adicionalmente, a análise sistêmica ainda buscou evidenciar quais os temas de pesquisa que estão sendo utilizados no ambiente científico. Foi possível constatar que os estudos chamam a atenção para a utilização das práticas contábeis, alguns estão utilizando teorias advindas de outras áreas com a contabilidade gerencial, outros chamam a atenção para a elaboração de teorias específicas para a contabilidade gerencial ou suas práticas. Em alguns artigos houve questionamento da validade e empregabilidade das ferramentas nos ambientes organizacionais como modelos já existentes e não adaptados para a estrutura da entidade e, em outros defendendo a utilização como prática contábil no modelo já existente. 
$\mathrm{Na}$ análise da teoria/conceito base utilizadas nos estudos evidencia-se o uso destacado dos conceitos de planejamento estratégico, sistemas de informações gerenciais, teoria da prática e teoria institucional.

Em relação às abordagens utilizadas nos estudos, evidencia-se que 24 artigos (41\%) utilizam a abordagem econômica, 23 artigos (39\%) utilizam a abordagem social e 12 artigos (20\%) utilizam a abordagem comportamental.

Pode-se perceber que as teorias buscam compreender como as práticas contábeis podem ser aplicadas eficientemente nas organizações, tentando compreender o papel humano, tanto social como comportamental, ou os fatores econômicos nas mudanças dessas práticas contábeis.

Portanto, conclui-se que a situação da contabilidade gerencial sob o viés da comunidade científica está voltada para as mudanças nos cenários organizacionais que anseiam por novas abordagens da contabilidade gerencial, seja através da melhoria de uma técnica/teoria já existente, ou utilizando múltiplas teorias para elaborar ferramentas eficazes, as quais sejam possíveis de aplicar e que retornem informações úteis aos gestores.

Cabe destacar ainda, que nas mudanças das práticas contábeis que buscam acompanhar as necessidades de informações dos gestores, é essencial estas considerar o nível crescente de complexidade organizacional interna e externa. A demanda de informação depende da escolha das organizações, porém, são os gestores que desempenham a função de utilizar a informação na tomada de decisão.

A presente pesquisa encontrou as seguintes limitações: (i) seleção de artigos somente em bases internacionais; (ii) utilização de apenas um termo de pesquisa; (iii) busca pelo termo de pesquisa somente no título dos artigos; (iv) análise bibliométrica somente dos artigos do portfólio bibliográfico; (v) análise bibliométrica restrita aos autores, artigos, palavras-chave, periódicos, países e período; e (vi) análise sistêmica restrita ao enquadramento metodológico e as teorias/conceitos base.

Desta forma, sugere-se para futuras pesquisas: (i) selecionar os artigos em bases nacionais e internacionais para comparar resultados; (ii) utilizar outros termos de pesquisa; (iii) realizar a busca em outros campos, tais como resumo e palavras-chave; (iv) realizar a análise bibliométrica das referências dos artigos selecionados; ( $v$ ) realizar outras análises bibliométricas, tais como formação de redes de autores e instituições; (vi) realizar análise sistêmica que vise analisar outros conteúdos diferentes dos analisados no presente estudo, tais como: quais teorias tem se trabalhado em conjunto, em quais países, quais os temas emergentes em contabilidade gerencial, em quais contextos, qual os motivos da baixa inserção dos pesquisadores brasileiros.

\section{REFERÊNCIAS}

AGUIAR, Andson B.; GUERREIRO, Reinaldo. Processos de persistência e mudança de sistemas de contabilidade gerencial: uma análise sob o paradigma institucional. Universo contábil, v. 4, n. 3, p.06-24, jul./set, 2008.

AFONSO, Michele H. F.; SOUZA, Juliane V.; ENSSLIN, Sandra R.; ENSSLIN, Leonardo. Como construir conhecimento sobre o tema de pesquisa? Aplicação do processo PROKNOW-C na busca de literatura sobre avaliação do desenvolvimento sustentável. Revista de Gestão Social e Ambiental, v.5, n.2, p.47-62, 2011.

ALMEIDA, Lauro B.; ANTONELLI, Ricardo A.; SCHVIRCK, Eliandro; LONGHI, Fernanda L. Adoção, utilização e satisfação sobre as práticas de contabilidade gerencial pelas indústrias associadas e afiliadas ao SindimetalPR/Sudoeste: Um estudo piloto. Revista de Informação Contábil, v.5, n³, p.59-77, jul-set/2011.

ALVARADO, Rubén U. A Lei de Lotka na bibliometria brasileira. Ci.Inf. vol.31. Brasilia. P.14-20, 2002. ARAÚJO, Carlos A.. Bibliometria: evolução história e questões atuais. Em Questão, Porto Alegre, 12(1), 11-32, 2006. 
ARAÚJO, Elisson A. T.; SILVA, Wendel A. C. Pesquisa Científica em Contabilidade Gerencial nos ENANPADs de 2003 a 2008. Revista Universo Contábil, 6(3), 29-44, 2010.

BARDIN, Laurence. Análise de Conteúdo (7a ed.). Lisboa: Portugal, LDA, 2009.

BONNER, S. E.; HESFORD, J. W.; VAN DER STEDE, W. A. \& YOUNG, S. M. The most influential journals in academic accounting. Accounting, Organizations and Society, 31(7), 663-685, 2006.

BORTOLUZZI, Sandro C.; Ensslin, Sandra R.; Ensslin, Leonardo; VALMORBIDA, Sandra Mara I. Avaliação de desempenho em redes de pequenas e médias empresas: Estado da arte para as delimitações postas pelo pesquisador. Revista Eletrônica Estratégia e Negócios, 4(2), 202-222, 2011.

CAFÉ, Ligia; BRÄSCHER, Marisa. Organização da Informação e Bibliometria. Revista Ci. Inf. Florianópolis, p.54-75, 2008.

CALDAS, Miguel P. Paradigmas em estudos organizacionais: uma introdução à série. Revista Administração de Empresas-RAE, 45 (1), 53-57, 2005.

CARDOSO, Ricardo L.; MENDONÇA NETO, Octavio R.; RICCIO, Edson L.; SAKATA, Marici. C. G. Pesquisa Científica em Contabilidade entre 1990 e 2003. Revista de Administração de Empresas - RAE. São Paulo: 45 (2): 34-45, Abr./Jun, 2005.

CARDOSO, Ricardo L.; PEREIRA, Carlos A.; GUERREIRO, Reinaldo. Perfil das pesquisas em Contabilidade de Custos Apresentadas nos EnANPAD no período de 1998 a 2003. RAC. São Paulo. P.177-198, 2007.

CATAPAN, Anderson; LOUÇÃO, Andressa S.; CARVALHO, Bruno D.; IVASCO, Franciele F. Contabilidade Gerencial: um estudo bibliométrico dos anos 2002 a 2012. Revista Ciências Sociais em Perspectiva, 12(23), 1-16, 2013.

ENSSLIN, Leonardo. et al. ProKnow-C, Knowledge Development Process-Constructivist. Processo técnico com patente de registro pendente junto ao INPI, Brasil.Pesquisa Operacional, 30(1), 125-152, 2010.

ENSSLIN, Leonardo; ENSSLIN, Sandra R.; LACERDA, R. T. O.; \& Tasca, J. E. ProKnow-C, Knowledge Development Process- Constructivist. Processo técnico com patente de registro pendente junto ao INPI. Brasil, 2010.

FELIU, Vicente M. R.; Palanca, Mercedes B.. Desenvolvimento científico da contabilidade de gestão. Revista de Administração, 35(1), 98-106, 2000.

FREZATTI, Fábio; AGUIAR, Andson B., GUERREIRO, Reinaldo. Diferenciações entre a contabilidade financeira e a contabilidade gerencial: uma pesquisa empírica a partir de pesquisadores de vários países. USP. São Paulo. P.9-22, 2007.

FREZATTI, Fábio; BORBA, José. A. Análise dos traços de tendência de uma amostra das revistas científicas da área de contabilidade publicadas na língua inglesa. In: VII Congresso Brasileiro de Custos, 2000, Recife. VII Congresso Brasileiro de Custos, 2000.

FREZATTI, Fábio; Rocha, Welington; NASCIMENTO, Artur R. do; JUNQUEIRA, Emanuel. Controle Gerencial: Uma abordagem da contabilidade gerencial no contexto econômico, comportamental e sociológico. São Paulo: Atlas, 2009.

GARRISON, Ray H.; NORREN, Eric W.; BREWER, Peter C. Contabilidade Gerencial. 11. ed - Rio de Janeiro: LTC, 2007.

GIL, Antonio C. Métodos e técnicas de pesquisa social (5a ed.). São Paulo: Atlas,1999.

HESFORD, James W.; LEE, Sung-Han; VAN DER STEDE, Win A.; YOUNG, Mark S. (2007) Management Accounting: A Bibliographic Study. In C. S. Chapman, A. G. Hopwood \& M. D. Shields (Org.). Handbook of Management Accounting Research.

HORNGREN, Charles T.; SUNDEM, Gary L. E.; Stratton, William O. Contabilidade gerencial. 12 ed. São Paulo: Prentice-Hall, 2004.

Internacional Federation of Accountants [IFAC], International Management Accounting Practice Statements: Management Accounting Concepts, New York, 82-100, 1998.

KAPLAN, Robert S. The evolution of management accounting. The Accounting Review, 1984, 390-417.

KOBASHI, Nair Y.; Santos, Raimundo N. M. Arqueologia do Trabalho Imaterial: uma aplicação bibliométrica à análise de dissertações e teses. Revista Ci. Inf. Florianópolis, Esp., 106-115, 2008.

LEITE FILHO, Geraldo A. Padrões de Produtividade de Autores em Periódicos de Congressos na Área de Contabilidade no Brasil: Um Estudo bibliométrico. Revista de Administração Contemporânea,12(2), 533-554, 2008.

LOUDERBACK, Joseph G.; HOLMEN, Jay; DOMINIAK, Geraldine. Managerial accounting (9.ed) Cincinnati: SouthWestern College Publ, 2000.

LUNKES, Rogério J.; FELIU, Vicente M. R.; ROSA, Fabricia S. Pesquisa sobre orçamento na Espanha: Um estudo bibliométrico das publicações em contabilidade. Revista Universo Contábil, 7(3), 112-132, 2011. 
MACIAS-CHAPULA, Cesar A. O papel da infometria e da cienciometria e sua pespectiva nacional e internacional. Ciência da Computação, 27(2), 134-140, 1998.

MARTELETO, Regina M. Análise das Redes Sociais - aplicação nos estudos de transferências da informação. Ci. Inf. Brasília, v.30, n.1, p.71-81, 2001.

MARTINS, Gilberto de A.; SILVA, Renata B. C. da. Plataforma teórica - trabalhos do $3^{\circ}$ e $4^{\circ}$ congressos USP de Controladoria e Contabilidade: um estudo bibliométrico. Anais do Congresso USP de Controladoria e Contabilidade, São Paulo, SP, Brasil, 5, 2005.

MORAES, Roque. Análise de conteúdo. Revista Educação, Porto Alegre, 22(37), 7-32, 1999.

NASCIMENTO, Artur R. do; JUNQUEIRA, Emanuel; MARTINS, Gilberto de A. Pesquisa acadêmica em contabilidade gerencial no Brasil: análise e reflexões sobre teorias, metodologias e paradigmas. Revista de Administração Contemporânea-RAC, 14 (6), 2010.

OLIVEIRA, Elayne K. F.; BOENTE, Diego R. Análise bibliométrica da produção científica recente sobre contabilidade gerencial. Organizações em contexto, 8(15), 199-212, 2012.

OLIVEIRA, Marcelle C. Análise dos periódicos brasileiros de contabilidade. Revista Contabilidade \& Finanças, FEA/USP . São Paulo, n. 29, p. 68-86, maio/ago. 2002.

PADOVEZE, Clóvis L. Contabilidade Gerencial. IESDE Brasil S.A. Curitiba. 2012.

PARETO, V. Cours d'èconomique politique. Macmillan, London, 1897.

PEAVEY, Dennis E. It's time for a change. Management Accounting, p.31-5, Feb. 1990.

RIBEIRO, Henrique C. M. Contribuição do Congresso USP ao estudo da área temática Controladoria e Contabilidade Gerencial: uma Bibliometria. RACE, 12(2), 709-746, 2013.

RICHARDSON, Roberto J. (1999). Pesquisa Social: métodos e técnicas (3a ed.). São Paulo: Atlas.

SENGUPTA, I.N.:Bibliometrics, Infometrics, Scientometrics and Librametrics: Na Overview. 6²ibri, Vol.42, p.75-98. Copenhagem. Disponível em

http://pt.scribd.com/doc/157582177/Sengupta-Bibliometrics-Informetrics-Scientometrics-and-Librametrics-An-Overview/ acessado em 04/09/2013 às 15:03hs.

SEVERINO, Antônio J. (2007). Metodologia do Trabalho Científico (23ed). São Paulo: Cortez.

Souza, Marcos A., LISBOA, Lázaro P., ROCHA, Welington. Práticas de contabilidade gerencial adotadas por subsidiárias brasileiras de empresas multinacionais. Revista Contabilidade \& Finanças - FAE/USP, 14(32), 40-57.

TAGUE-SUTCLIFFE, Jean. An introduction to informetrics. Information Processing \& Management, 28(1), 1-3, 1992.

THEÓPHILO, Carlos R.; IUDÍCIBUS, Sérgio. Uma Análise crítico-epistemológica da produção científica em contabilidade no Brasil. UNB Contábil, 8(2), 147-175, 2005.

TURNEY, Peter B.B., ANDERSON, Brian. Accounting for continuous improvement. Massachusetts: MIT Sloan Management Review, 30(2), 37-47, 1989.

VALMORBIDA, Sandra M. I.; ENSSLIN, Sandra R.; Ensslin, Leonardo. Avaliação de desempenho na Administração de Universidade Pública: Análise Bibliométrica da Literatura Nacional e Internacional. Administração Pública e Gestão Social, 5(3), 116-125, 2013.

VANTI, Nádia A. P. Da bibliometria à webometria: uma exploração conceitual dos mecanismos utilizados para medir o registro da informação e a difusão do conhecimento. Revista Ciência da Informação, v. 31, n. 2, p. 152-162, 2002.

VILELA, Lilian O. Aplicação do PROKNOW-C para seleção de um portifólio bibliográfico e análise bibliométrica sobre avaliação de desempenho da gestão do conhecimento. Revista Gestão Industrial, v.8, n.1, p.76-92, 2012.

VOLPATO, Gilson L. Publicação Científica. Botucatu: Santana, 2002.

WITTGENSTEIN, Ludwig. Investigações filosóficas. Petrópolis: Vozes, 1996. 